\title{
Restoring Esthetics and Function in a Patient with Amelogenesis Imperfecta - A Multidisciplinary Approach
}

\author{
Neeraja Turagam* and Durga Prasad Mudrakola
}

Department of Prosthodontics, AIMST University, Semeling, Jalan Bedong, 08100, Kedah, Malaysia

\begin{abstract}
Amelogenesis imperfecta has been described as a complex group of inherited conditions that disturbs the developing enamel structure and exists independent of any related systemic disorder. It is a rare dental disease but represents a great restorative challenge for dentists. This clinical case report describes the oral rehabilitation of a young adult male patient diagnosed with hypoplastic amelogenesis imperfect, anodontia and decreased vertical dimension. This challenge was corrected by gingivectomy, gingivoplasty, by achieving the desired crown length keeping in view the biological width. Fixed metal ceramic restorations were given to enhance the aesthetics, masticatory function, eliminate the teeth sensitivity and to enhance the overall personality of the patient. Follow-up visits were scheduled at 3 months, 6 months and 1 year. No esthetic or functional problems were seen after the follow up period. The goal of the treatment was to achieve function, reduce sensitivity, protect enamel and improve esthetics.
\end{abstract}

Keywords: Amelogenesis imperfecta; Hypoplastic type; Genetic; Splint; Metal ceramic single crowns; Metal ceramic bridges

\section{Introduction}

Amelogenesis imperfecta $(\mathrm{Al})$ is a diverse collection of inherited conditions primarily affecting the quality and/or quantity of dental enamel occasionally in conjunction with other dental, oral and extraoral tissues [1] encompassing a complicated group of conditions that demonstrate developmental alterations in the structure of the enamel in the absence of a systemic disorder [2,3]. Also known by varied names such as Hereditary enamel dysplasia, Hereditary brown enamel, Hereditary brown opalescent teeth, this defect is entirely ectodermal, since mesodermal components of the teeth are basically normal [4].

The clinical manifestations vary greatly among individuals, with discoloration (yellow, brown, or gray), generalized areas of exposed dentin, pitted enamel with an increased susceptibility to plaque accumulation, caries, and hypersensitivity to temperature changes [5]. This genetic disorder is known to be associated with the malfunction of the enamel forming proteins ameloblastin, enamelin, tuftelin, and amelogenin [6].

The AI trait can be transmitted by either autosomal dominant, autosomal recessive, or X-linked modes of inheritance. It is reported to have an incidence of one person in every $14,000[7,8]$. Mutations in amelogenin gene (AMELX) cause X-linked amelogenesis imperfecta, while mutations in the enamelin gene (ENAM) cause autosomalinherited forms of amelogenesis imperfecta that control amelogenesis and follows inheritance patterns of autosomal-dominant, autosomal recessive or X- linked modes of transmission. Recent reports involve kallikrein-4 (KLK4), MMP-20 and DLX3 genes in the aetiologies of some cases [9-11].

Classifications of AI are primarily based on phenotype and mode of inheritance. The most commonly used classification was proposed in 1988 by Witkop, and revised by Nusier in 2004. Based on enamel appearance and hypothesized developmental defects, AI is classified as 4 patterns: hypoplastic, hypomaturation, hypocalcified, and hypomaturation-hypoplastic [11-14].

At least fifteen subtypes of AI exist when phenotype and mode of inheritance are considered. Based on literature regardless of subtype, AI patients have similar oral complications like teeth sensitivity, poor dental aesthetics, multiple impacted teeth, congenitally missing teeth, open occlusal relationship and decreased occlusal vertical dimension [15-17]. Other dental anomalies associated with AI include, but are not limited to, multiple impacted teeth, congenitally missing teeth, open occlusal relationship, and taurodontism [1,17-19]. Historically, patients with AI have been treated with multiple extractions and the fabrication of complete dentures. Recently, several studies have illustrated the use of stainless steel crowns, adhesive casting, over denture, porcelain veneers, ceramics, and composite resin veneers to restore dentitions mutilated by severe attrition [20-23].

The aim of this article is to outline the management of aesthetics and function with prosthetic approach in a patient with amelogenesis imperfecta of hypoplastic type accompanied with anodontia.

\section{Case Report}

A 26-year old male patient reported to the department of Prosthodontics for replacement of missing teeth. He also complained of sensitivity to hot and cold, wear of posterior teeth and compromised masticatory function. The patient expressed dissatisfaction with the appearance of his teeth as they appeared yellowish in color. A detailed medical, dental and social history was obtained which revealed that his primary dentition was affected in the same manner. The patient's hair, skin and nails were normal.

Extra oral examination had no abnormalities. The intraoral examination revealed missing upper anterior teeth $11,12,13,21,22,23$, hypoplastic enamel surface and yellowish discoloration of the teeth (Figure 1). The tooth surfaces were rough with pitting. Attrition was present on the occlusal surfaces of all the molars due to which the vertical dimension was reduced (Figures 2 and 3 ). There was generalized loss of contact and contour of teeth. The enamel layer was

*Corresponding author: Neeraja Turagam, Department of Prosthodontics, AIMST University, Semeling, Jalan Bedong, 08100, Kedah, Malaysia, Tel: 0164036659; E-mail: neer222@gmail.com

Received January 26, 2015; Accepted February 06, 2015; Published February 10, 2015

Citation: Turagam N, Mudrakola DP (2015) Restoring Esthetics and Function in a Patient with Amelogenesis Imperfecta - A Multidisciplinary Approach. Dentistry 5 285. doi:10.4172/2161-1122.1000285

Copyright: (c 2015 Turagam N, et al. This is an open-access article distributed under the terms of the Creative Commons Attribution License, which permits unrestricted use, distribution, and reproduction in any medium, provided the original author and source are credited. 


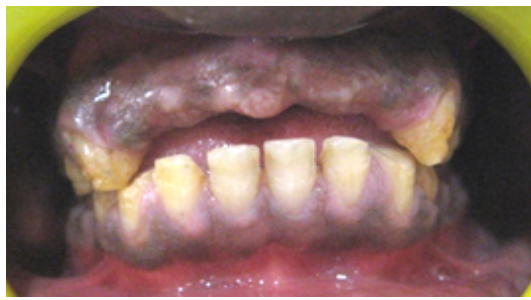

Figure 1: Frontal view.

nearly absent in the occlusal portion of the molars and the exposed dentin was brown and hypersensitive. However, there was no carious defects and no impacted teeth present in the dentition. Teeth 15,16,25, $26,27,35,36,37,45,46,47$ had reduced clinical crowns on measuring with a probe. The patient's oral hygiene was fair.

A Panoramic radiograph showed generalized defective enamel in all teeth with its radio density being the same as that of dentin along with missing upper anteriors. The patient was questioned about the presence of similar abnormalities in his family including parents, brothers, sisters, and grandparents. He stated his brother had similar appearance to his teeth.

A provisional diagnosis of hypomature AI was proposed along with a differential diagnosis of environmental enamel hypoplasia, Dentinogenesis imperfecta and dentin dysplasia. The diagnosis of hypoplastic, pigmented, autosomal recessive type of amelogenesis imperfecta with partial anodontia was confirmed on the basis of typical family history, clinical and radiological examination.

\section{Treatment}

After radiographic examination of crown/root ratio, root number and morphology of the present teeth, construction of full-mouth metal reinforced porcelain fixed bridge restoration was planned sparing the third molars. Maxillary and mandibular complete-arch impressions were made using irreversible hydrocolloid (Zelgan, Alginate, Fast Set; Dentsply Intl ) impression material. Diagnostic casts were fabricated from Type- III dental stone (Pankaj Industries, Mumbai, India) and mounted on a semi-adjustable articulator (Articulator \#3140; Whip Mix Corp) using a face-bow transfer (\#8645 Quick Mount Face-Bow; Whip Mix Corp) and a centric relation record (Take 1 Bite; Kerr Corp, Orange, Calif) (Figure 4). The articulator was programmed using protrusive and lateral records (Coprwax Bite Wafers; Heraeus Kulzer, South Bend, Ind). The diagnostic waxing was done. The interdisciplinary approach was followed because of the complex needs of the patient. The patient was informed of the diagnosis and the treatment plan, which he accepted.

First oral prophylaxis was done and oral hygiene instructions were given, the patient was placed on a $0.12 \%$ chlorohexidine gluconate oral rinse, with a recommended use of twice daily. Super seal desentizing paste (Phoenix Dental Inc.) was applied after scaling on the teeth to reduce sensitivity as it forms a biological bond with the vital dentinal surface. The occlusal vertical dimension was $2 \mathrm{~mm}$ lower than normal. A hard acrylic splint cured hard was fabricated (Figures 5 and 6). The patient was advised to use it for the next few months form the correction of the vertical dimension. The adaptation of the temporomandibular joint and masticatory muscles was carefully reviewed periodically every 15 days during 4 months and necessary corrections were done.

Periodontal surgery was planned to overcome the decreased crown root ratio which was done as a part of the crown lengthening procedure with consideration for biologic width dimensions for maxillary (Figure 7) and mandibular (Figure 8) posterior teeth. Gingivectomy and gingivoplasty was performed by using orban's knife and Blake gingivectomy knife by the periodontist to achieve the desired crown length. Without violating the biological width, the surgical site was

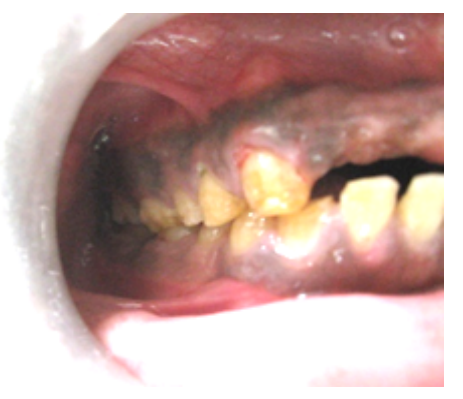

Figure 2: Left lateral.

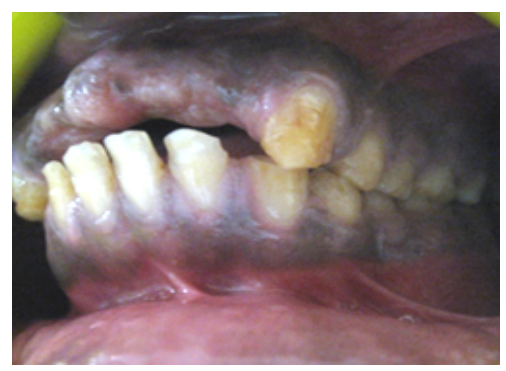

Figure 3: Right Lateral.

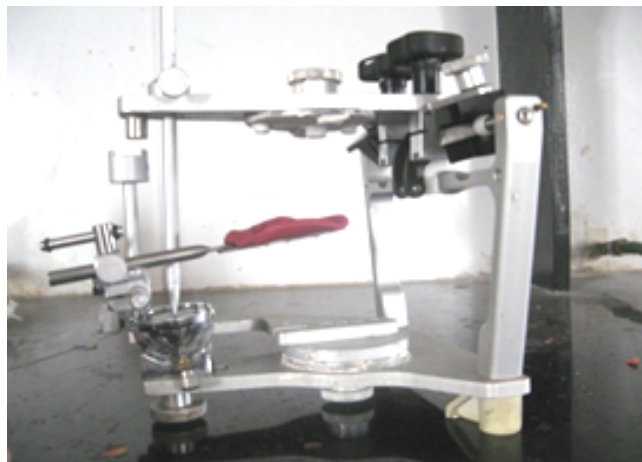

Figure 4: Facebow transfer via Whipmix Articulator.

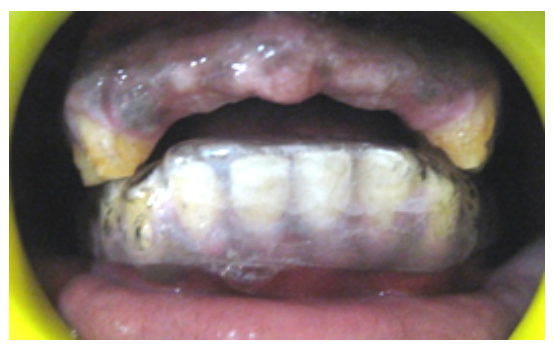

Figure 5: Acrylic Splint on Mandibular teeth. 


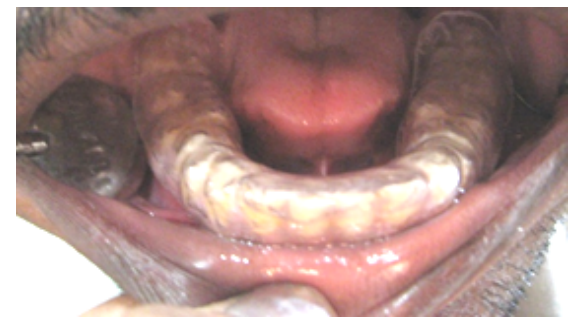

Figure 6: Occlusal view with splint.

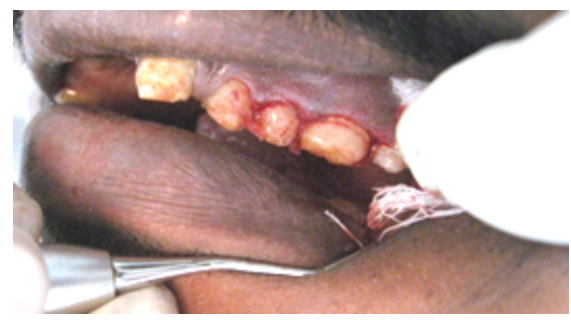

Figure 7: Crown Lengthening for Maxillary teeth.

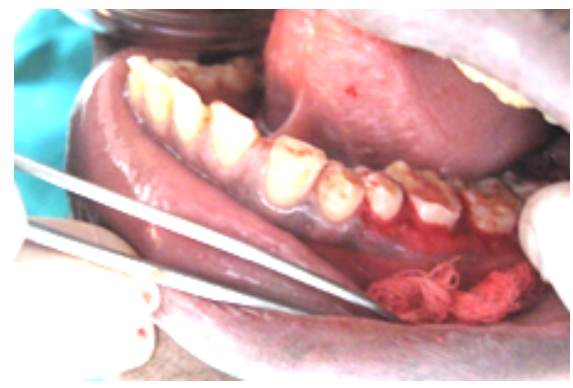

Figure 8: Crown Lengthening for Mandibular teeth.

allowed to heal for 3 weeks (Figure 9). The patient was advised to use mouth wash and super seal for next few days after surgery.

After evaluation of radiograph and diagnostic wax up it was anticipated that remaining dentin thickness would be insufficient for protection of pulp during tooth preparation. So intentional endodontic therapy was performed for teeth 33, 43, and 44 by an Endodontist. The appropriate shade was then selected using the VITA shade guide (Vita Zahnfabrik, Badsackingen, Germany) prior to preparation. In order to avoid trauma to the gingival sulcus a thin retraction cord was inserted into the sulcus prior to preparation. The facial surfaces of the mandibular anterior teeth were prepared. A $2 \mathrm{~mm}$ facial and lingual reduction was performed, creating a chamfer cervical finish line. The incisal edges of the teeth were prepared to allow overlap of the restoration. All tooth preparations were completed without sharp line angles. All the mandibular teeth were prepared for metal-ceramic restorations (Figure 10).

Impressions were made with addition polyvinyl siloxane material (Reprosil, Dentsply/Caulk; Milford, DE, USA) in special trays. Heat-cured provisional restorations were fabricated using methyl methacrylate acrylic resin. The provisional restorations were temporarily cemented using Provicol, eugenol free $\mathrm{Ca}(\mathrm{OH}) 2$ cement (Voco, Cuxhaven, Germany). From the impressions, casts were made and mounted in an articulator to produce, metal-ceramic individual crowns in the mandibular anteriors for esthetics and metal ceramic bridges for the posterior teeth.The metal frameworks were evaluated intraorally to determine the marginal fit. A metal trial insertion, prior to glazing of the ceramic material was performed, which enabled the final occlusal refinement (Figure 11). The crowns were then completed in the laboratory and cemented with luting glass ionomer cement (GC, Tokyo, Japan) (Figure 12).

Then, the maxillary teeth 13 and 23 were prepared to receive a metal-ceramic fixed prosthesis for replacement of the missing teeth $11,12,21,22$ along with all the maxillary posterior teeth (Figure 13).

Heat-cured provisional restorations were fabricated using methyl methacrylate acrylic resin. The provisional restorations were temporarily cemented using Provicol, eugenol free $\mathrm{Ca}(\mathrm{OH})_{2}$ cement (Voco, Cuxhaven, Germany). Final impressions for prepared teeth were made with addition polyvinyl siloxane material (Reprosil, Dentsply/Caulk; Milford, DE, USA). Casts were made and mounted in an articulator. All restorations were fabricated with IPS Empress 2 materials (Ivoclar Vivadent AG, Schaan, Liechtenstein) according to

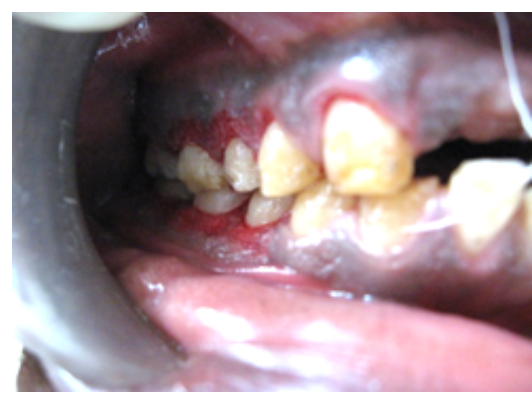

Figure 9: After Crown Lengthening

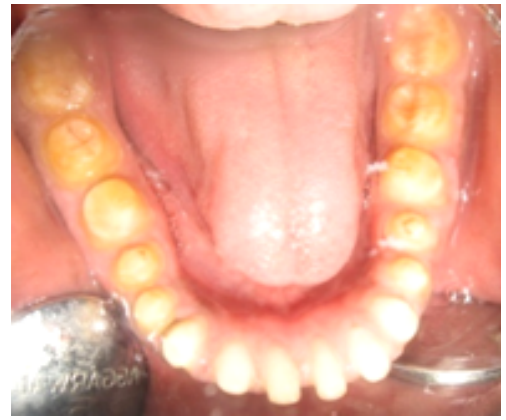

Figure 10: Preparation of all Mandibular teeth

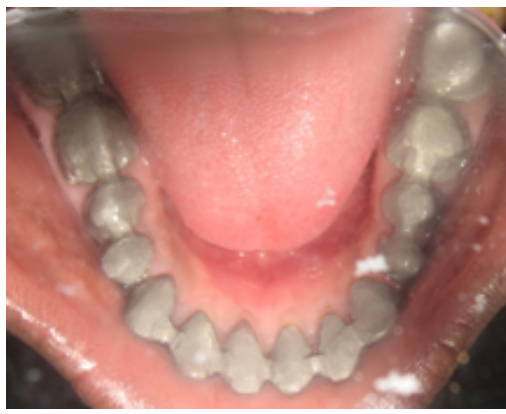

Figure 11: Metal Try-in of Mandibular teeth. 


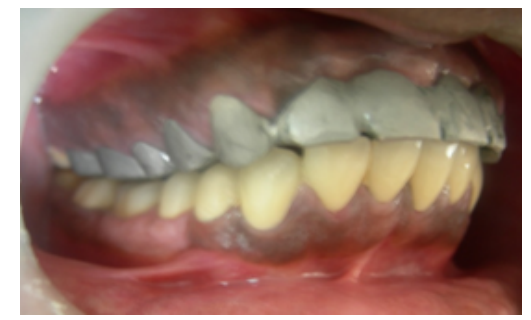

Figure 12: Cementation of metal ceramic crowns.

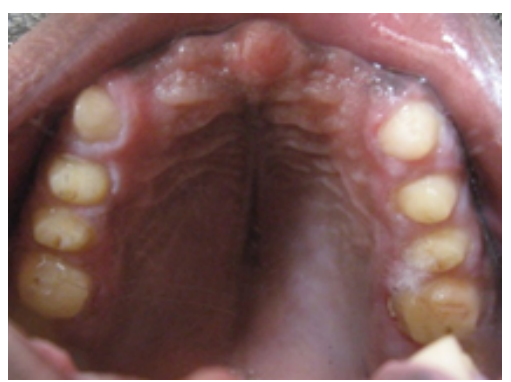

Figure 13: Preparation of Maxillary teeth.

the manufacturer's directions. After completion, the metal trial of the crowns was evaluated for fit on the prepared teeth (Figure 14). They were then luted with a resin luting agent (Variolink II high viscosity; Ivoclar Vivadent AG) (Figure 15).

The anterior metal-ceramic fixed dental prosthesis metal-ceramic crown and were satisfactory both aesthetically and functionally at the end of 1 year of clinical service and the patient's oral hygiene was satisfactory. Pt was very happy with his appearance, more confident during smile and highly enthusiastic concerning his work (Figure 16).

\section{Discussion}

The predominant clinical manifestations of affected individuals with "Amelogenesis Imperfecta" (AI) are enamel hypoplasia (enamel is seemingly correctly mineralized, but thin), hypomineralization (subdivided into hypomaturation and hypocalcification), or a combined phenotype, which is seen in most cases. The trait of AI can be transmitted by an autosomal- dominant, autosomal-recessive, or $\mathrm{X}$-linked mode of inheritance $[9,24,25]$.

The treatment options vary considerably depending on several factors such as the age of the patient, socioeconomic status, periodontal condition, loss of tooth structure, severity of the disorder, and, most importantly, the patient's cooperation [26]. There are a number of alternatives for the treatment of anterior teeth affected by AI [27-29]. For many years the most predictable and durable aesthetic restoration of anterior teeth has been achieved with complete crowns [30]. Several authors prefer full porcelain restorations as the treatment modality of their patient with AI [6,31-35]. However, the advances in the field of esthetic dentistry, especially in bonding to dentin, help practitioners to restore function and aesthetics to an acceptable level $[1,6,36]$. Nevertheless, marginal adaptation and bonding problems have been pointed out as disadvantages of laminate veneers [35]. In the present case, full-mouth metal-reinforced porcelain restorations were preferred to redouble the mechanical durability, recover aesthetics and protect the residual dentin. The clinician has to consider the long-term prognosis of the treatment outcome. This clinical report describes the fabrication of fixed metal ceramic single crowns for the restoration of mandibular anterior teeth to modify teeth's color, shape, and length and metal ceramic bridges to restore all the remaining teeth in functional occlusion and to close the space. The complexity of the management of patients with $\mathrm{AI}$ requires careful considerations of patient expectations and requests, an interdisciplinary approach which is critical for a successful outcome and patient satisfaction. In our case, meticulous attention to detail, from diagnosis to post delivery monitoring, allowed a controlled and logical treatment sequence.

\section{Conclusion}

The treatment plan for patients with AI is related to many factors including the age of the patient, the socio-economic status, the type and severity of the disorder and its intra oral manifestation [26,37]. Treatment for amelogenesis imperfecta includes replacement of the missing teeth and protecting the existing dentition. The dentist has to balance the decision for early intervention and long time survival of the restorations to prevent later problems some dental anomalies may accompany the AI cases. In these cases, multidisciplinary approach is important for treatment success.

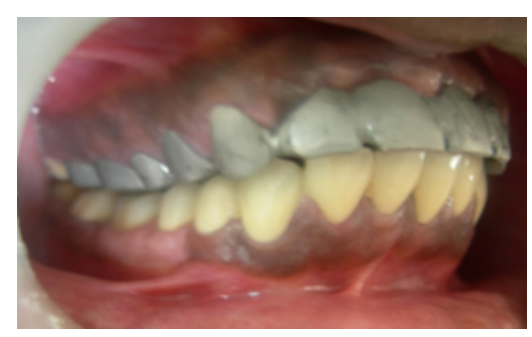

Figure 14: Metal Try-in of Maxillary teeth.

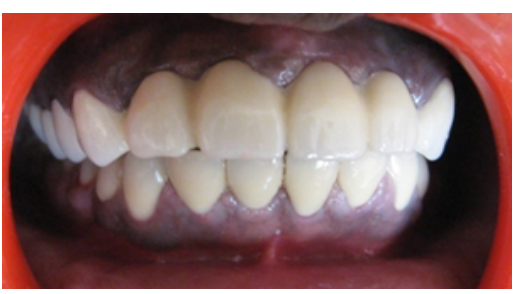

Figure 15: Final Cementation.

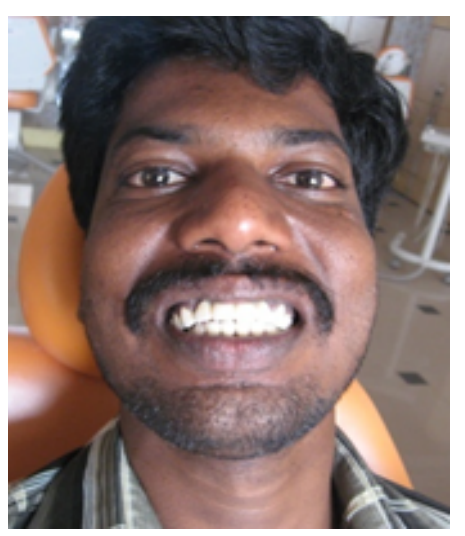

Figure 16: Post Cementation patient satisfaction. 
Citation: Turagam N, Mudrakola DP (2015) Restoring Esthetics and Function in a Patient with Amelogenesis Imperfecta - A Multidisciplinary Approach. Dentistry 5: 285. doi:10.4172/2161-1122.1000285

The challenges in this case report were satisfactory. The reduced vertical dimension corrected by splinting also restored function of TMJ and muscles of mastication, decreased crown length by periodontal surgical procedures, problems of sensitivity was resolved super seal application, non-vital teeth was restored by endodontic procedures and the esthetics were enhanced by the metal ceramic restorations by prosthodontists. Making it a multi-disciplinary way to treat a complex case with utmost patient satisfaction.

\section{References}

1. Sengun A, Ozer F (2002) Restoring function and esthetics in a patient with amelogenesis imperfecta: a case report. Quintessence Int 33: 199-204.

2. Emin Murat Canger, Peruze Celenk, Murat Yenisey, Selcen Zeynep Odyakmaz (2010) Amelogenesis Imperfecta, Hypoplastic Type associated with some dental abnormalities : A Case Report. Braz Dent J 21: 170-174.

3. Neville BW, Damm DD, Allen CM, Bouquot JE (2005) Chapter 2: Abnormalities of teeth. In: Oral and Maxillofacial Pathology. ( $2^{\text {nd }}$ edtn $)$ Saunders: an imprint of Elsevier 89.

4. Chaudhary M, Dixit S, Singh A, Kunte S (2009) Amelogenesis imperfecta: Report of a case and review of literature. J Oral Maxillofac Pathol 13: 70-77.

5. Hart PS, Wright JT, Savage M, Kang G, Bensen JT, et al. (2003) Exclusion of candidate genes in two families with autosomal dominant hypocalcified amelogenesis imperfecta. Eur J Oral Sci 111: 326-331.

6. Gokce K, Canpolat C, Ozel E (2007) Restoring function and esthetics in a patient with amelogenesis imperfecta: a case report. J Contemp Dent Pract 8: 95-101.

7. Witkop CJ Jr (1988) Amelogenesis imperfecta, dentinogenesis imperfecta and dentin dysplasia revisited: problems in classification. J Oral Pathol 17: 547-553.

8. WK Seow (1993) Clinical diagnosis and management strategies of amelogenesis imperfecta variants," Pediatric Dentistry 15: 384-393.

9. Bundzman ER, Modesto A (1999) Hypomaturation amelogenesis imperfecta: account of a family with an X-linked inheritance pattern. Braz Dent J 10: 111116.

10. Sekiguchi H, Tanakamaru H, Minaguchi K, Machida Y, Yakushiji M (2001) A case of amelogenesis imperfecta of deciduous and all permanent teeth. Bull Tokyo Dent Coll 42: 45-50.

11. Crawford PJ, Aldred M, Bloch-Zupan A (2007) Amelogenesis imperfecta. Orphanet J Rare Dis 2: 17.

12. Neville BW, Douglass DD, Allen CM, Bouquot JE (2004) Abnormalities of teeth. In: Oral and Maxillofacial Pathology ( $2^{\text {nd }}$ edtn) Pennsylvania: Elsevier 89-94.

13. Bailleul-Forestier I, Molla M, Verloes A, Berdal A (2008) The genetic basis of inherited anomalies of the teeth. Part 1: clinical and molecular aspects of nonsyndromic dental disorders. Eur J Med Genet 51: 273-291.

14. Santos MC, Line SR (2005) The genetics of amelogenesis imperfecta: a review of the literature. J Appl Oral Sci 13: 212-217.

15. Rao S, Witkop CJ Jr (1971) Inherited defects in tooth structure. Birth Defects Orig Artic Ser 7: 153-184.

16. Sundell S, Valentin J (1986) Hereditary aspects and classification of hereditary amelogenesis imperfecta. Community Dent Oral Epidemiol 14: 211-216.

17. Aldred MJ, Crawford PJ (1988) Variable expression in Amelogenesis imperfecta with taurodontism. J Oral Pathol 17: 327-333.

18. Ooya K, J Nalbandian, Noikura T (1988) Autosomal recessive rough hypoplastic amelogenesis imperfecta. A case report with clinical, light microscopic, radiographic, and electron microscopic observations. Oral Surgery Oral Medicine and Oral Pathology 65: 449-458.

19. KMS Ayers, BK Drummond, Harding WJ, Salis SG, PN Liston (2004) Amelogenesis imperfecta- multidisciplinary management from eruption to adulthood. Review and case report. New Zealand Dental Journal 100: 101-104.

20. Lamb DJ (1976) The treatment of amelogenesis imperfecta. J Prosthet Dent 36: 286-291.

21. Harley KE, Ibbetson RJ (1993) Dental anomalies--are adhesive castings the solution? Br Dent J 174: 15-22.

22. Patel RRA, Hovijitra S, Kafrawy AH, Bixler D (1991) X linked (recessive) hypomaturation amelogenesis imperfecta: a prosthodontic, genetic, and histopathologic report. The Journal of Prosthetic Dentistry 66: 398-402.

23. Walter B (1991) Prosthetic rehabilitation of a case of total amelogenesis imperfect. Actualites Odonto-Stomatologiques 45: 213-226.

24. Seow WK (1993) Clinical diagnosis and management strategies of amelogenesis imperfectavariants. Pediatr Dent 15: 384-393.

25. Rajendran $R$ (2009) Chapter: 1. Developmental disturbances of oral and paraoral structures. In: Rajendran R, Sivapathasundharam B, editors. Shafer' Textbook of Oral Pathology. (6thedtn) Elsevier 48.

26. Sari T, Usumez A (2003) Restoring function and esthetics in a patient with amelogenesis imperfecta: a clinical report. J Prosthet Dent 90: 522-525.

27. Pulgar Encinas R, García-Espona I, Navajas Rodriguez de Mondelo JM (2001) Amelogenesis imperfecta: diagnosis and resolution of a case with hypoplasia and hypocalcification of enamel, dental agenesis, and skeletal open bite. Quintessence Int 32: 183-189.

28. Greenfield R, lacono V, Zove S, Baer P (1992) Periodontal and prosthodontic treatment of amelogenesis imperfecta: a clinical report. J Prosthet Dent 68: 572-574.

29. Bouvier D, Duprez JP, Pirel C, Vincent B (1999) Amelogenesis imperfecta-a prosthetic rehabilitation: a clinical report. J Prosthet Dent 82: 130-131.

30. Peumans M, Van Meerbeek B, Lambrechts P, Vanherle G (2000) Porcelain veneers: a review of the literature. J Dent 28: 163-177.

31. Siadat H, Alikhasi M, Mirfazaelian A (2007) Rehabilitation of a patient with amelogenesis imperfecta using all-ceramic crowns: a clinical report. J Prosthet Dent 98: 85-88.

32. Toksavul S, Ulusoy M, Turkun M, Kümbüloğlu O (2004) Amelogenesis imperfecta: the multidisciplinary approach. A case report. Quintessence Int 35: $11-14$.

33. Sadighpour L, Geramipanah F, Nikzad S (2009) Fixed rehabilitation of an ACP PDI class III patient with amelogenesis imperfecta. J Prosthodont 18: 64-70.

34. Kostoulas I, Kourtis S, Andritsakis D, Doukoudakis A (2005) Functional and esthetic rehabilitation in amelogenesis imperfecta with all-ceramic restorations: a case report. Quintessence Int 36: 329-338.

35. Ozturk N, Sari Z, Ozturk B (2004) An interdisciplinary approach for restoring function and esthetics in a patient with amelogenesis imperfecta and malocclusion: a clinical report. J Prosthet Dent 92: 112-115.

36. Christensen GJ (1999) Porcelain-fused-to-metal vs. nonmetal crowns. J Am Dent Assoc 130: 409-411.

37. Nel JC, Pretorius JA, Weber A, Marais JT (1997) Restoring function and esthetics in a patient with amelogenesis imperfecta. Int $\mathrm{J}$ Periodontics Restorative Dent 17: 478-483. 